Research Paper

\title{
Construction of a human monoclonal antibody against bFGF for suppression of NSCLC
}

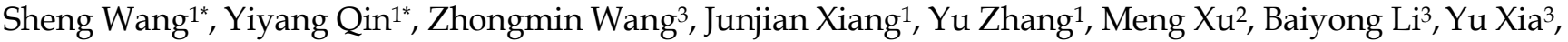 \\ Peng Zhang 3 , Hong Wang ${ }^{1 凶}$ \\ 1. Guangdong Province Engineering Research Center for antibody drug and immunoassay, College of Life Science and Technology, Jinan University, \\ Guangzhou 510632, Guangdong Province, China. \\ 2. Department of Oncology, the First Affiliated Hospital of Jinan University, Guangzhou 510632, Guangdong Province, China. \\ 3. Akeso Biopharma, Inc., Zhongshan, 528400, Guangdong Province, China \\ * These authors contributed equally to this work. \\ $\triangle$ Corresponding author: Hong Wang; E-mail: wanghong368@yahoo.com; Tel: 008613602455251 \\ (c) Ivyspring International Publisher. This is an open access article distributed under the terms of the Creative Commons Attribution (CC BY-NC) license \\ (https://creativecommons.org/licenses/by-nc/4.0/). See http://ivyspring.com/terms for full terms and conditions.
}

Received: 2017.12.07; Accepted: 2018.02.13; Published: 2018.04.30

\begin{abstract}
Compelling evidence implicates that overexpression of basic fibroblast growth factor (bFGF) and fibroblast growth factor receptor 1 (FGFRI) in non-small cell lung cancer (NSCLC) drives tumor progression, can serve as prognostic biomarkers or therapeutic targets for NSCLC patients. But at present, we still lack of effective drugs for bFGF. The preparation of monoclonal antibodies against bFGF or to understand its mechanism of action is urgently need. Previously, we used hybridoma technology to produce a murine anti-bFGF monoclonal antibody (E12). However, E12 carries risks of heterogeneity and immunogenicity. In the present work, we produced three humanized variants $(\mathrm{H} 1 \mathrm{~L} 1, \quad \mathrm{H} 2 \mathrm{~L} 2$ and $\mathrm{H} 3 \mathrm{~L} 3)$ based on $\mathrm{E} 12$ by substituting residues in or near the complementarity-determining region (CDR). In addition, we thoroughly explored $\mathrm{VH} / \mathrm{VL}$ domain combinations to simulate full-length $\operatorname{lgG} 1$ antibodies using computational protein design. $\mathrm{H} 3 \mathrm{~L} 3$ was selected for further study, as it demonstrated the best humanization and strongest affinity for bFGF. Specially, humanization of H3L3's light chain and heavy chain were $100 \%$ and $98.89 \%$, respectively. The FGF2 neutralizing effect of H3L3 were confirmed by ELISA. We also found that H3L3 can effectively suppress the growth and angiogenesis of cancer through reduce the phosphorylation of AKT and MAPK. Moreover, H3L3 dramatically reduced tumor size and micro-vessel density in nude mice. Altogether, our study demonstrates that $\mathrm{H} 3 \mathrm{~L} 3$ exerts anti-tumor effects by impeding NSCLC development.
\end{abstract}

Key words: bFGF; Antibody humanization; Non-Small Cell Lung; Targeted therapies

\section{Introduction}

Lung cancer is among the most common cancers in the world with high morbidity and mortality rates. Specifically, non-small cell lung cancer (NSCLC) comprises $85 \%$ of all lung cancers and has a 5 -year survival rate of only $4 \%$ in cases of metastatic disease[1]. Although current cancer treatments such as chemotherapy, radiotherapy and immunotherapy can improve overall survival (OS) and progression-free survival (PFS), only a subgroup of patients respond to these therapies. Compounding the problem, tumors are often not detected until they have progressed to an advanced stage. However, angiogenesis or vascular remodeling is a major process of tumor cell metastasis and proliferation. Angiogenesis is a complex procedure involving several cell types. The maturation of endothelial cells to capillary tubes is a critical step $[2,3]$ and is the basis of forming a tumor-associated vascular network. Cancer cells utilize such angiogenic mechanisms to stimulate tumor growth. Stromal cells or tumor cells can secrete growth factors or chemokines that promote formation of blood vessels or lymph vessels. 
Thus, finding effective targets to suppress angiogenesis for NSCLC treatment is urgently needed.

bFGF is a member of the FGF family. It is a cationic polypeptide of 155 amino acids that is highly conserved, associated with the angiogenesis or matrix remodeling in cancers[4]. bFGF interacts with the high-affinity FGFR and the low-affinity paran sulfate proteoglycans(HSPGs) [5]. Binding of bFGF to FGFRs induces a conformational change resulting in dimerization[6] and activation of the receptors' intracellular tyrosine kinase domains and downstream signaling pathways producing different pathological responses[7]. Moreover, dysregulation of FGF/FGFRs signaling in cancers contributes to pathogenesis[8]. Accumulating evidence has revealed that expression of bFGF and FGFRs is significantly elevated in the sera of multiple tumor types[9-11] and is associated with tumor recurrence[12]. bFGF and FGFR1 expression is commonly aberrant in early-stage NSCLC, and is associated with tumor growth, invasion, metastasis, and angiogenesis[13-16].Thus, targeting bFGF /FGFRs may be an effective way to inhibit formation of blood vessels in tumors.

Several bFGF/FGFRs inhibitors have shown promising anti-angiogenic activity. Both monoclonal antibodies and tyrosine kinase inhibitors (TKIs) have been developed to target FGF2/FGFRs signaling networks[17-19]. Although FGFR TKIs, such as BIBF1120 and BMS-582, can block receptor signaling through competitive inhibition of ATP binding with the cytoplasmic domain of EGFR, FGFR and VEGFR, their low specificity and various side effects put a brake on clinical treatment. We attempted to prepare monoclonal antibodies to block the interaction between bFGF and FGFR1, to affect cell proliferation and angiogenesis. To this end, we previously produced an anti-bFGF murine monoclonal antibody (E12) by hybridoma technology, that showed promising antitumor activity[20, 21]. However, E12 would cause a potent anti-murine antibody response in humans. Therefore, it is necessary to humanize the antibody before conducting detailed pre-clinical and clinical studies. We have developed three novel human mAb against bFGF (H1L1, H2L2 and H3L3) based on E12 with computational protein design methods. We found that H3L3 can bind to bFGF specifically and displayed better humanization than the others. In addition, H3L3 could effectively target bFGF, weaken the interaction between bFGF and FGFR1, and prevent activation of downstream signal pathways. These activities exerted a strong antitumor activity in vitro and in vivo. Therefore, our study reveals that H3L3 is a promising candidate to inhibit the invasion, proliferation, migration, and angiogenesis of NSCLC.

\section{Materials and methods}

\section{Cell culture and animals}

Human lung cancer cells (H460) and human umbilical vein endothelial cells (HUVEC) were grown in DMEM (Gibco) media supplemented with $10 \%$ fetal bovine serum (Gibco) and 1\% penicillin/streptomycin at $37^{\circ} \mathrm{C}$ in a $95 \%$ humidity atmosphere containing $5 \%$ $\mathrm{CO}_{2}$.

BALB/c-nu mice (female, 5-6 weeks) were purchased from Beijing HFK Bioscince Co. Ltd, Beijing, China. All the animals used in the experiments were treated humanely in accordance with the Institutional Animal Care and Use Committee Guidelines of Jinan University.

\section{Production of fully Humanized Monoclonal Antibodies}

The CDR-grafted sequence was constructed by selecting fully human antibody VL and VH domains that had the highest sequence similarity with the murine antibody (E12) in NCBI BLAST. Each homologous human VL and VH domain of interest was substituted with E12 complementaritydetermining regions (CDRs) to produce the CDR-grafted humanized variants (H1L1, H2L2 and H3L3). To obtain a stable structure, the energy of model was minimized using proprietary structural optimization software until the energy gradients reached the optimal level. Recombinant plasmids, containing the various optimized combinations of light and heavy chains, were transiently transfected into mammalian $293 \mathrm{~F}$ cells $\left(2 \times 10^{6} \mathrm{cells} / \mathrm{ml}\right)$ at a density of $0.5 \mathrm{mg} / \mathrm{L}$ and cultured for 5 days before the cultural supernatant was collected.

\section{Immunofluorescence assay}

bFGF and H3L3 were conjugated with PE and FITC, respectively. All steps were performed according to the product brochure. H460 cells were seeded in 6-well plates and incubated overnight at $37^{\circ} \mathrm{C}$. The cells were washed with PBS three times prior to treatment with H3L3-FITC + bFGF-PE or bFGF-PE alone. After $1 \mathrm{~h}$ of treatment the cells were imaged using laser scanning confocal microscopy.

\section{Cell viability assay}

The effects of H3L3 on cell viability were evaluated by CCK 8 assay. $\mathrm{H} 460$ cells were seeded to 96-well plates at 3000 cells/well and incubated overnight at $37^{\circ} \mathrm{C}$. After treating with $0.5 \%$ FBS in DMEM for $12 \mathrm{~h}$, the experimental group was treated with serially diluted H3L3 plus $20 \mathrm{ng} / \mathrm{mL}$ bFGF for 72 $\mathrm{h}$. The cells were then incubated with Cell Counting Kit-8 solution at $37^{\circ} \mathrm{C}$ for $3 \mathrm{~h}$ (CCK-8; Dojindo 
Laboratories, Kumamoto, Japan) and detected at $\mathrm{OD}_{450}$ in the ELISA reader (BioTek).

\section{Wound healing assay}

H460 cells were seeded in 6-well plates and incubated overnight at $37^{\circ} \mathrm{C}$. When the cells had grown to confluence, a cell-free area was introduced in the monolayer using a pipette tip. The test and control groups received different treatments (H3L3: $200 \mu \mathrm{g} / \mathrm{ml} \mathrm{H} 3 \mathrm{~L} 3+20 \mathrm{ng} / \mathrm{mL}$ bFGF; Control: 20 $\mathrm{ng} / \mathrm{mL} \mathrm{bFGF}$ ). The cells were captured for analysis at $0 \mathrm{~h}$ and $24 \mathrm{~h}$.

\section{Western blot assay}

H460 cells were seeded in 6-well plates, treated with serially diluted H3L3 and $0.5 \%$ FBS with or without bFGF $(20 \mathrm{ng} / \mathrm{mL}$ ) and incubated for $48 \mathrm{~h}$. Cells were lysed with RIPA lysis buffer at $4^{\circ} \mathrm{C}$ for 10 min (Bey-otime Biotechnology, Suzhou, China). The lysates were transferred into new EP tubes and centrifuged at $12,000 \mathrm{~g}$ for $10 \mathrm{~min}$ at $4^{\circ} \mathrm{C}$. The Pierce BCA Protein Assay Kit (Thermo Scientific, Rockford, IL, USA) was used to quantify total protein. The proteins were separated by $12 \%$ SDS- PAGE and transferred to PVDF membrane (Millipore) and then blocked with $5 \%$ nonfat milk at $37^{\circ} \mathrm{C}$ for $1 \mathrm{~h}$, incubated with rabbit anti-t/p-MAPK (4695/4370; Cell Signaling Technology, Danvers, MA, USA) and rabbit anti-t/p-Akt (4691/4060; Cell Signaling Technology) at $4^{\circ} \mathrm{C}$ overnight. The membrane was then incubated with the HRP-conjugated goat anti-rabbit IgG for $1 \mathrm{~h}$ at $37^{\circ} \mathrm{C}$. The blots were detected with an immobilon Western chemiluminescent HRP Substrate (Millipore) according to the manufacturer's protocol.

\section{Transwell assay}

HUVEC cells were transferred to inserts of each transwell chamber (BD Biosciences, Bedford, MA, USA) with CM of H460 cell cultures. H3L3 (200 $\mu \mathrm{g} / \mathrm{ml}$ ) and isotype IgG was added to the inserts and incubated at $37^{\circ} \mathrm{C}$ for $24 \mathrm{~h}$. Controls received the medium with DMSO. The lower chambers contained $600 \mu \mathrm{L}$ complete medium as a chemoattractant. After $24 \mathrm{~h}$, the cells on the upper side of the filters were mechanically removed, and those that had migrated into the lower side were fixed with $75 \%$ ethanol (20 min), stained by $0.1 \%$ crystal violet (Meryer, Shanghai, China), and imaged with a computerized imaging system.

\section{Tube formation assay}

Matrigel matrix $(50 \mu \mathrm{l} /$ well $)$ was added into 96-well plates. The plates were incubated for $30 \mathrm{~min}$ at $4^{\circ} \mathrm{C}$ and then for $30 \mathrm{~min}$ at $37^{\circ} \mathrm{C}$. HUVEC $\left(5 \times 10^{4}\right.$ cells/well) suspended in DMEM complete medium with $20 \mathrm{ng} / \mathrm{mL}$ bFGF were seeded to each well.
Purified H3L3 $(200 \mu \mathrm{g} / \mathrm{ml})$ and isotype antibody were added and incubated for $16 \mathrm{~h}$. Tube formation was observed under a microscope and tube numbers were counted in five random high-power fields.

\section{In vivo xenograft studies}

H460 cells $\left(5 \times 10^{6}\right)$ were subcutaneously injected into the back of BALB/c-nu mice. Once the tumors were palpable, the BALB/c-nu mice were randomly assigned into five treatment groups (five mice per group). H3L3 $(25 \mathrm{mg} / \mathrm{kg}, 12.5 \mathrm{mg} / \mathrm{kg}, 6.25 \mathrm{mg} / \mathrm{kg})$, Cisplatin $(2.5 \mathrm{mg} / \mathrm{kg})$, or PBS was injected into the tumors. All groups were injected six times at 3 day intervals. A vernier caliper was used to measured tumor size in two dimensions. Tumor volume $\left(\mathrm{mm}^{3}\right)$ was calculated as $v=1 / 2\left(a \times b^{2}\right)$. a: length of tumor, $b$ : width of tumor. The rate of tumor growth inhibition was calculated as (1-the mean of the tumor volume of treated groups/the mean of the tumor volume of PBS group) $\times 100 \%$.

\section{Statistical analysis}

Data are expressed as the mean and standard deviation (SD). $\mathrm{P}<0.05$ were considered statistically significant. Assays were performed at least three times independently.

\section{Results}

\section{Humanization of the murine antibody E12}

The anti-bFGF murine antibody (E12) was selected as a template to construct the human monoclonal antibody. To achieve maximum humanization, we altered the constant and CDR regions to mimic that of its most similar aligned peptide from a human germline antibody producing three strains of humanized antibodies (Fig. 1A, B). After making all possible single substitutions to simulate the human germline sequence, the number of mutations produced less diversity among light chains compared to heavy chains, and the humanization of heavy and light chains in H1L1, H2L2 and H3L3 were 93.26, 82.22; 94.38, 92.22; and $100 \%, 98.89 \%$ respectively (Fig. 1E, F). In addition, we assessed the affinity of these antibodies by ELISA, and found that they all display favorable affinities and stabilities at high temperatures, have alkali resistance, and can withstand repeated freeze-thaw cycles (Supplementary Table S1, Fig. S1). Based on these analyses, we chose the humanized monoclonal antibody H3L3 for further investigation. In order to verify whether the spatial structure was changed after the antibody humanized, we compared the interactions of bFGF with E12 and H3L3 by homology modeling. The structural stability was evaluated by rotameric energy. Molecular docking analysis showed 
$\begin{array}{lllllll}1 & 10 & 20 & 30 & \text { CDR1 } & 40 & 50\end{array}$

A $_{\text {WT }}$ VQLQQSGAGL VKPGTSVKLS CKASGFTFTE YVIHWVKQRS GQGLEWIGWF

H1 ---V-----EV ----S------ ----------- -------R--- ----------

H2 ---V----EV -----S----- ---------- ------R-AP ----------

H3 ---V----EV K---S---V- ---------- ------R-AP ----------

$\begin{array}{llllll}\text { CDR2 } & 60 & 70 & 80 & 90 & 100\end{array}$

WT YPGSGTIKYN EKFKDKARLT ADKSSSTVYM ELNRLTSEDS GVYFCARHED

H1 ---------- Q-----R---- -----T----- --S------T ---Y------

H2 -------N-A Q----R-TI- ----T--A-- --SS-R---T ---Y------

H3 --------N-A Q--QGRVTI- ----T--A-- --SS-R---T A--Y------

CDR3 $110 \quad 120$

WT DEYGDTGWFG YWGQGTLVTV SS

H1 ---------- ---------- --

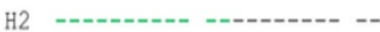

H3 ---------- ---------- --

$\begin{array}{lllllll}\text { B } & 1 & 10 & 20 & \text { CDR1 } 30 & 40 & 50\end{array}$

WT DIQMTQSPAS LSASVGATVT ITCRASENIY SYLAWYQQKQ GKSPQLLVYN

L1 ---------S- -------DR-- ----------- ----------- --S-K-----

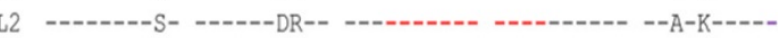

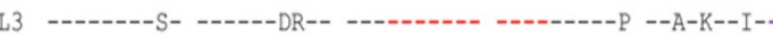

$\begin{array}{lllllll}\text { CDR2 } & 60 & 70 & 80 & 90 & \text { CDR3 } & 100\end{array}$

WT TKILGEGVPS RFSGSGSGTQ FSLKINSLQP EDFGTYYCQH HFDTYTFGGG

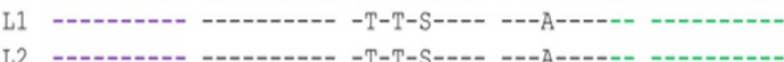

L3 --S--S---- ----------- -T-T-S---- ---A------ ---------

106

WT TKLEIK

------

-

3 -----

E

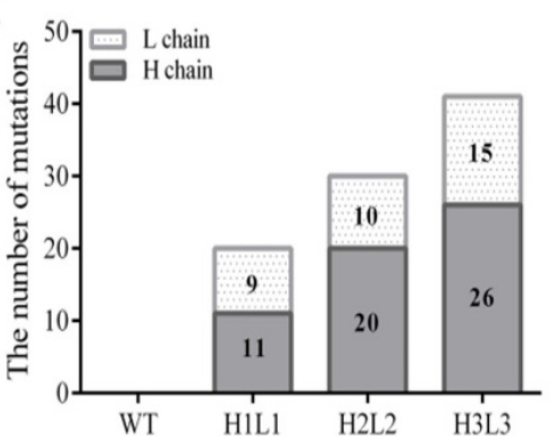

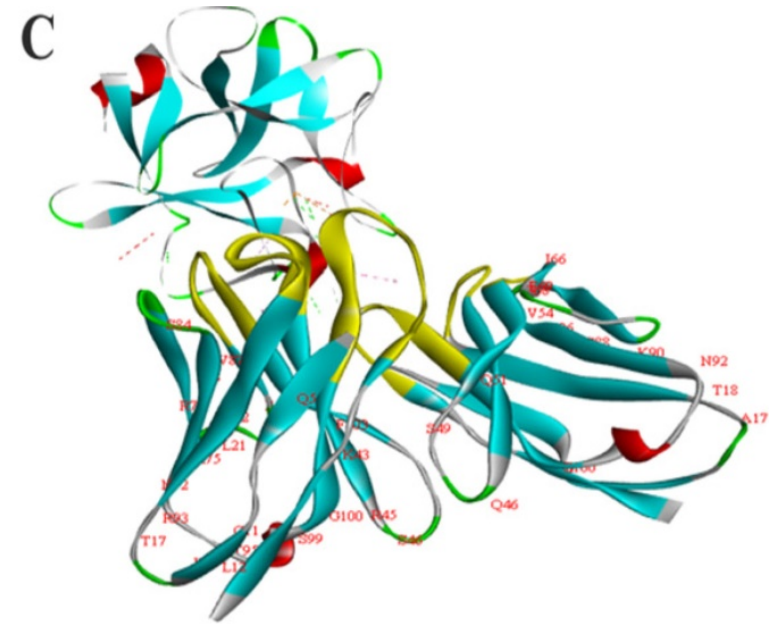

D

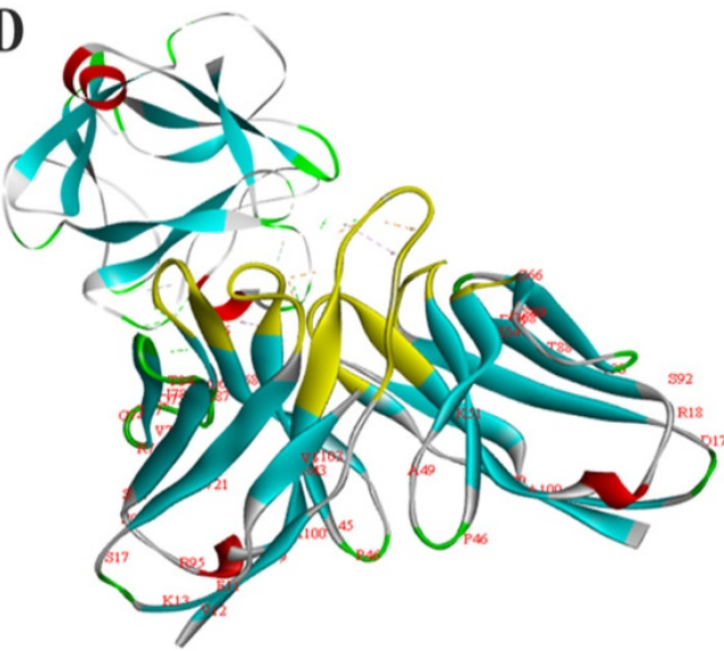

$\mathbf{F}$

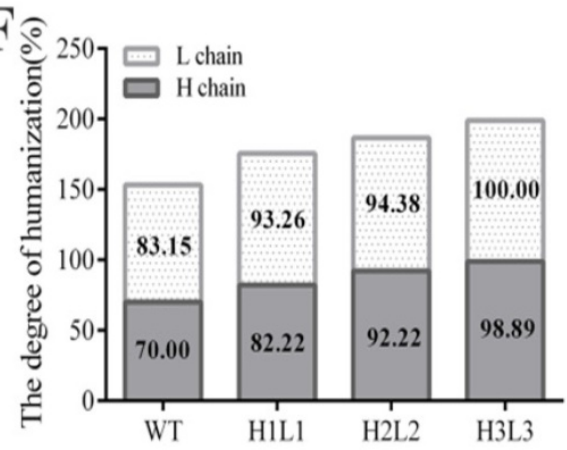

Figure 1. Sequence analysis the humanization of murine antibody. (A)CDR of heavy chain; (B) CDR of light chain; (C) Molecular docking of mouse monoclonal antibody(E12) and (D) humanized monoclonal antibody(H3L3) with bFGF. (E)The number of base substitutions in light chain ( $L$ chain) and heavy chain (H chain). (F) The degree of humanization among $\mathrm{L}$ chains and $\mathrm{H}$ chains in WT(E12), H1L1, H2L2 and H3L3. WT represents the murine monoclonal antibody; light chain(White); heavy chain(gray).

that the humanized CDR regions did not affect the binding of H3L3 to bFGF (Fig. 1C, D). These data indicate that H3L3 is stable and is theoretically able to bind bFGF.

\section{H3L3 significantly inhibits the proliferation and migration of $\mathrm{H} 460$ cells, and migration and angiogenesis of HUVEC cells}

After the identification and purification of H3L3 by reducing and non reducing SDS-PAGE and SEC-HPLC assays, we determined that the heavy and light chains assembled into a complete antibody with a molecular weight of $150 \mathrm{KD}$ (Supplementary Fig. S2). We further investigated its effect on the viability of $\mathrm{H} 460$ cells using the CCK8 kit. At $500 \mu \mathrm{g} / \mathrm{ml}$ of H3L3, the inhibition rate reached $66.82 \%$, and this inhibitory capacity was dose-dependent in a certain range (Fig. 2A). In addition, the migration rate of H460 cells was markedly decreased to $60.00 \%$ compared to the control after $24 \mathrm{~h}$ in wound healing assay (Fig. 2C, F). The migration of endothelial cells plays a key role in tumor angiogenesis[22]. Migration 

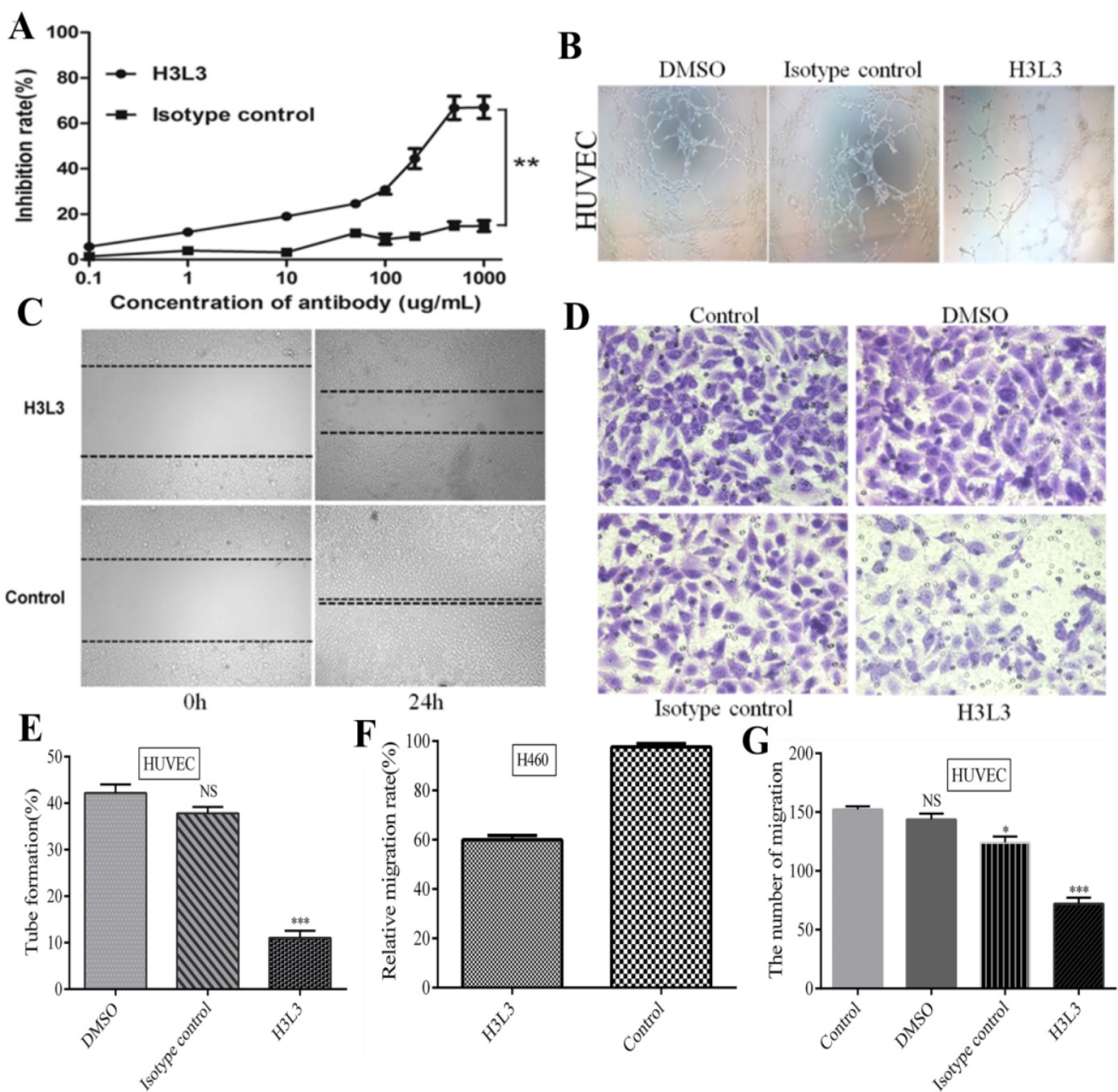

D
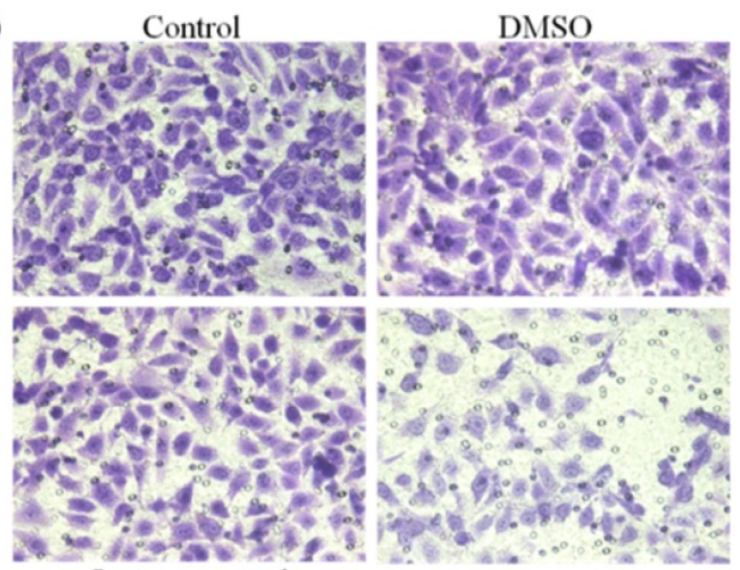

$24 \mathrm{~h}$
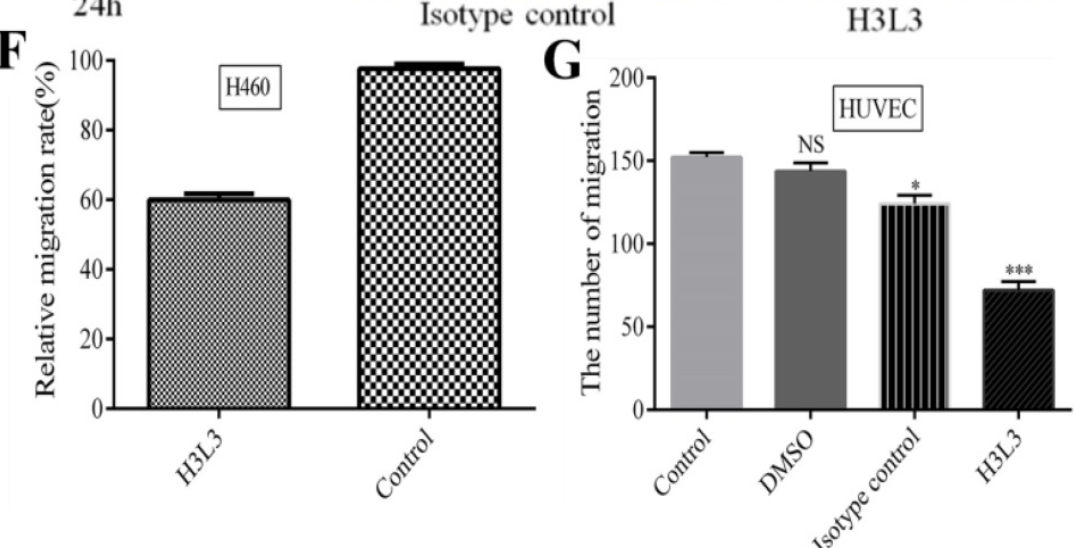

Figure 2. H3L3 effectively inhibited the proliferation, migration, angiogenesis of $\mathbf{H} 460$ and HUVEC cells. (A)The proliferation of H460 cells were assayed by CCK8-kit. (B) Tubules were sparser in H3L3 cultures compared to their corresponding control(0.01\%DMSO) in HUVEC. (C) H3L3 suppresses the migration of H460 cells at Oh and 24h measured by a Wound healing assay (200×magnification). (H3L3: 200ug/ml H3L3 + 20ng/mL bFGF; Control: $+20 \mathrm{ng} / \mathrm{mL}$ bFGF). (D)HUVEC were treated with the condition medium(CM) of $\mathrm{H} 460$ cell supernatant, adding with DMSO $(0.01 \%)$, Isotype IgG and H3L3, respectively, complete by Boyden chamber assay.(E-G) Histograms represented the percentage of tube formation $(E)$ and relative migration rate in the wound healing assay $(F)$ numbers of migration of HUVEC cells in the Transwell assay $(G)$. Data are presented as the mean \pm SD of three independent experiments performed in triplicate. NS: no significant; $* \mathrm{P}<0.05, * * \mathrm{P}<0.01, * * * \mathrm{P}<0.001$.

of HUVEC cells was significantly reduced in the H3L3-treated group compared to the control in transwell assay (Fig. 2D, G). Tube formation rates in groups treated with DMSO, the isotype antibody control, and H3L3 were $42.2 \%, 37.8 \%$, and $11.0 \%$, respectively (Fig. 2B, E). These results demonstrate that H3L3 can effectively inhibit the proliferation and migration of $\mathrm{H} 460$ cells, and that it can also decrease the migration and angiogenesis of HUVEC cells.

\section{H3L3 inhibits the proliferation of $\mathrm{H} 460$ cells via FGF2/FGFR signaling pathways}

We next investigated the signaling pathways through which H3L3 influences cancer progression. It has been reported that $\mathrm{PI} 3 \mathrm{~K} / \mathrm{AKT} / \mathrm{mTOR}$ and MAPK/ERK are the main signaling pathways that affect cancer cells proliferation[23]. Western blot revealed that H3L3 markedly inhibited the phosphorylation of MAPK and AKT in H460 cells in a dose-dependent manner (Fig. 3A). We then used immunofluorescence assays to explore whether H3L3 could block the binding of bFGF to extracellular FGFRs. The results implied that bFGF could effectively bind FGFRs and that H3L3 may inhibit the ability of bFGF to bind FGFRs on the cell surface, thereby preventing the activation of the downstream FGF2/FGFR signaling pathways (Fig. 3B). 
A<smiles>[Te][Te]</smiles>
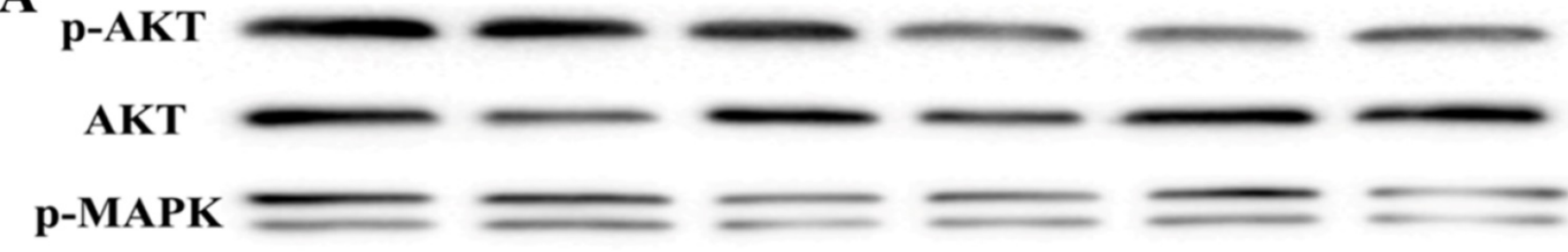

\author{
MAPK
}

\title{
GAPDH
}
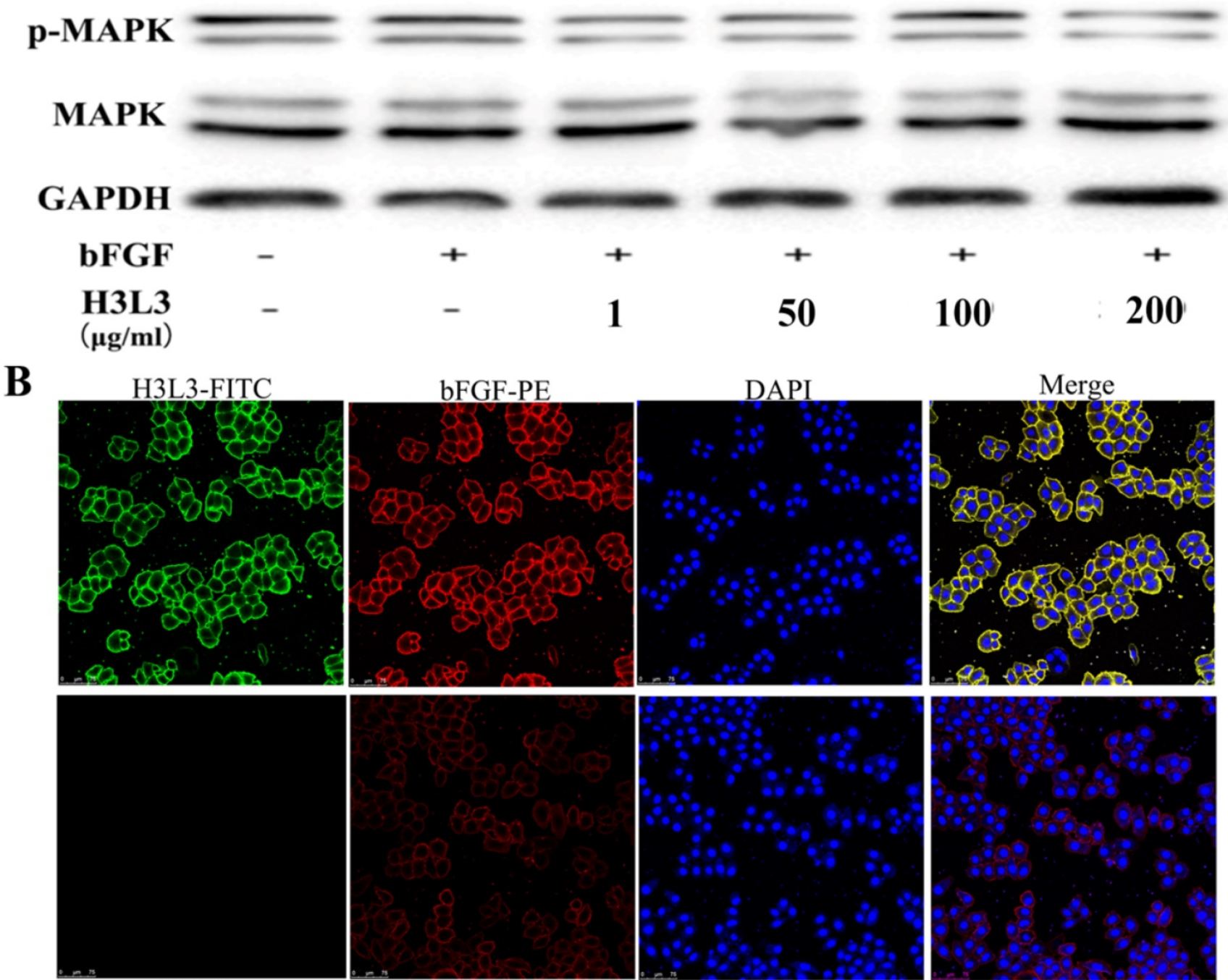

H3L3
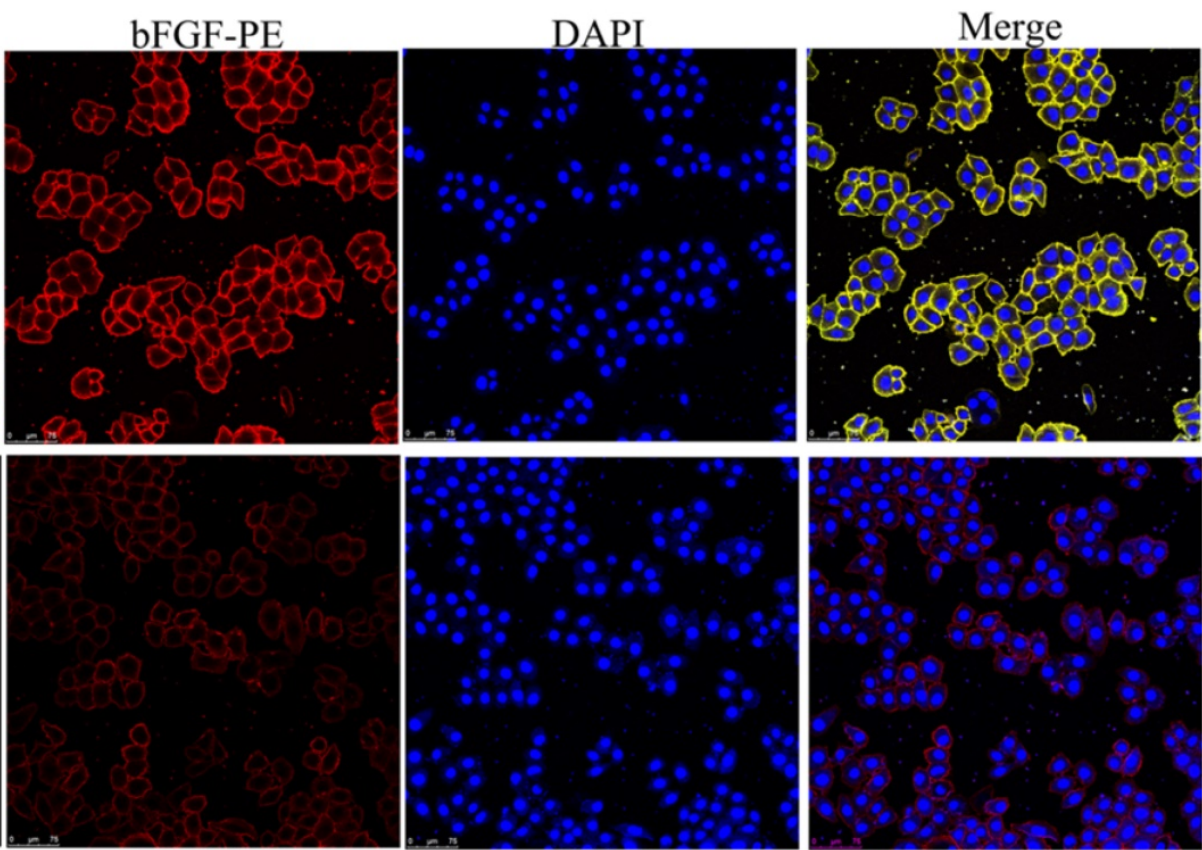

bFGF-PE

DAPI

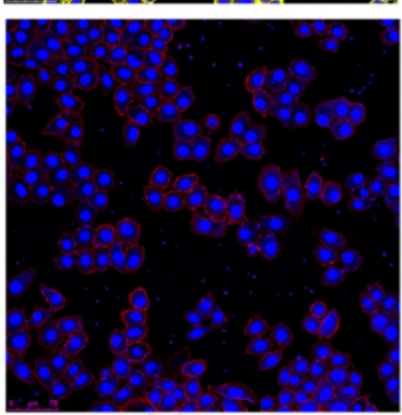

Merge

Figure 3. The mechanism and combined form of $\mathbf{H} 3 \mathrm{~L} 3$ in $\mathbf{H} 460$ cells. (A)H3L3 suppresses the proliferation of H460 cell by MAPK and AKT signaling pathways by Western blot assay. GAPDH was used as the reference control. (B) Immunofluorescence assay revealed the binding of H3L 3 to bFGF and then interacted with FGFRs by using confocal microscope. The date showed as statistical analysis of the mean OD450 in various group, presented as the mean \pm SD of three independent experiments performed in triplicate.

\section{H3L3 suppresses tumor growth in vivo}

To investigate whether H3L3 exerts potent anti-tumor effects in vivo, we establish the tumor model via hypodermic injection of $\mathrm{H} 460$ cells in nude mice. Consistent with the results in vitro, H3L3 could markedly inhibit tumor growth in comparison with the control group(PBS) in a dose dependent manner (Fig. 4A). The tumor volumes were larger in the H3L3-treated group than Cisplatin-treated group. However, the tumor volume in the H3L3-treated group was significantly reduced compared to the control (Fig. 4B, C). Inhibition of tumor growth reached $68.84 \%$ with H3L3 treatment $(25 \mathrm{mg} / \mathrm{mL})$ (Fig. 4D). To further investigate the side effects of H3L3 in nude mice, we measured the weight of BABL/C-nu mice every three days after injection of H3L3. We found the weight of BABL/c-nu mice was relatively stable (Fig. 4E). Moreover, H3L3 visibly reduced the formation of micro-vessel density in tumor xenografts (Fig. 4F, G). These results indicate that H3L3 is able to suppress tumor growth in vivo.

Taken together, our data indicate that the fully human monoclonal antibody (H3L3) could effectively suppress the progression or growth of NSCLC by targeting bFGF/FGFRs. 


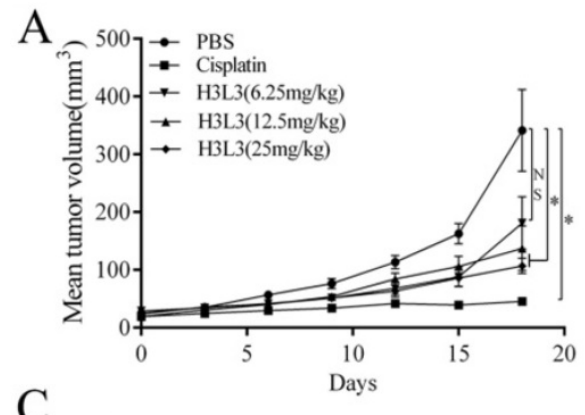

\section{$\mathrm{B}$}

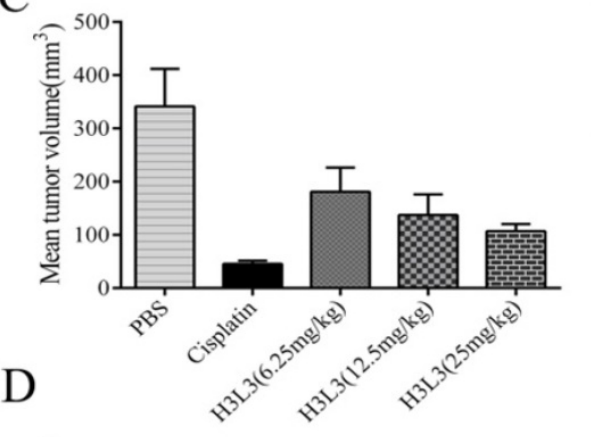

$\mathrm{H} 3 \mathrm{~L} 3$
$(6.25 \mathrm{mg} / \mathrm{kg})$

PBS

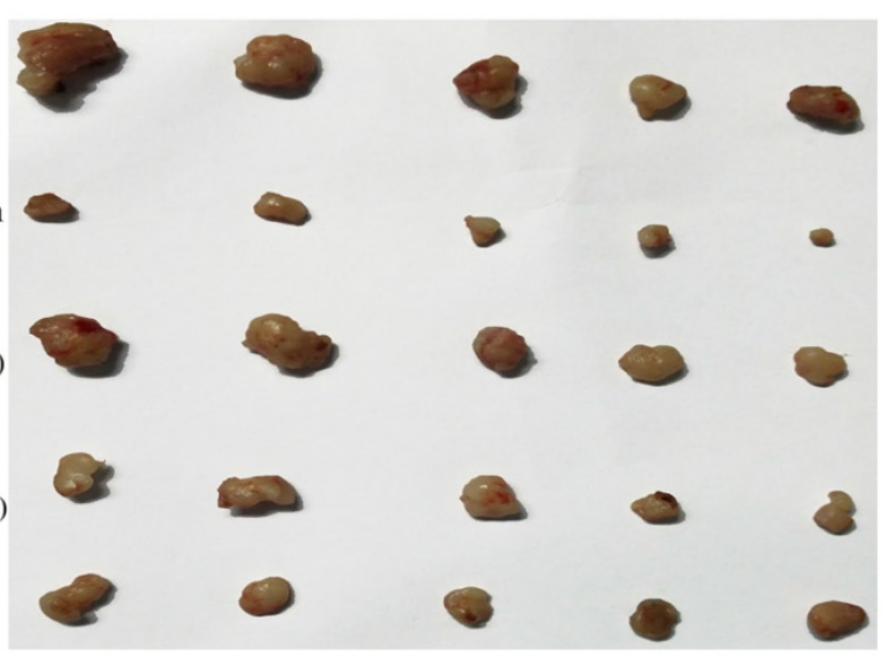

$(25 \mathrm{mg} / \mathrm{kg})$

$\mathrm{H} 3 \mathrm{~L} 3$
$(12.5 \mathrm{mg} / \mathrm{kg})$

H3L3

(5)

E
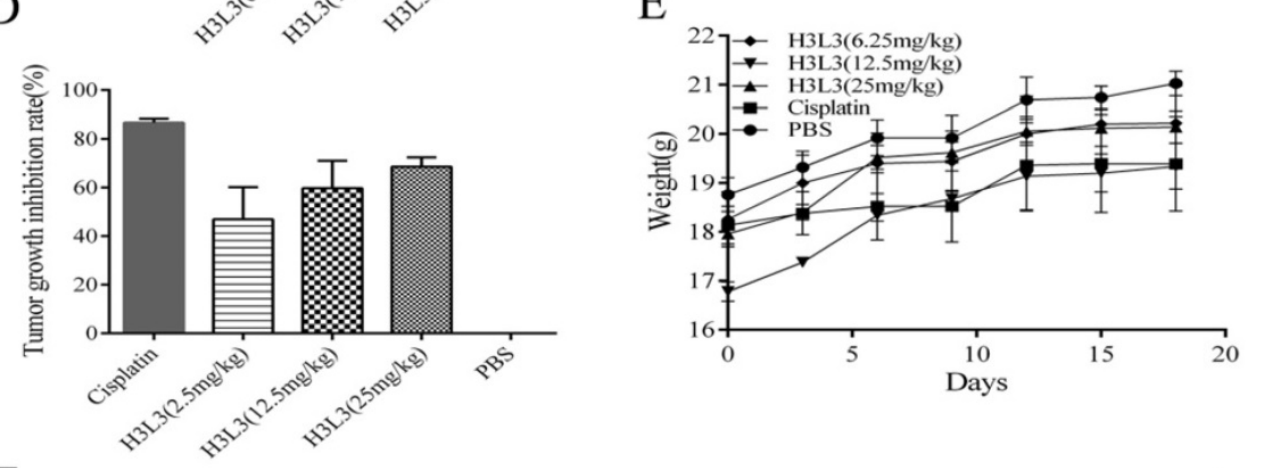

F

H3L3(25mg/kg)

H3L3(12.5mg/kg)

H3L3(6.25mg/kg)
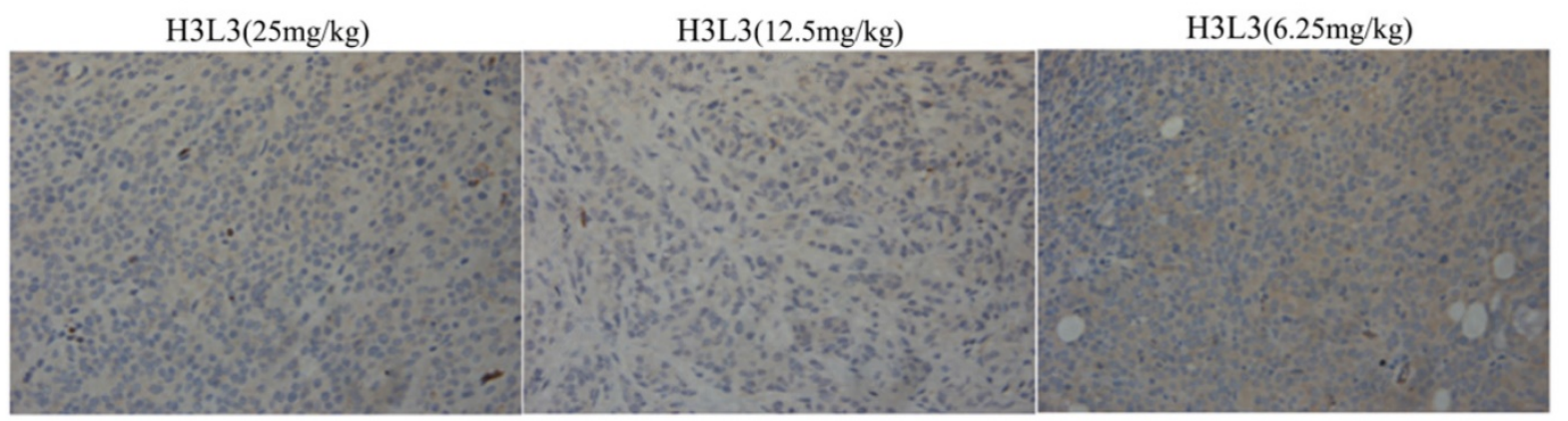

Cisplatin

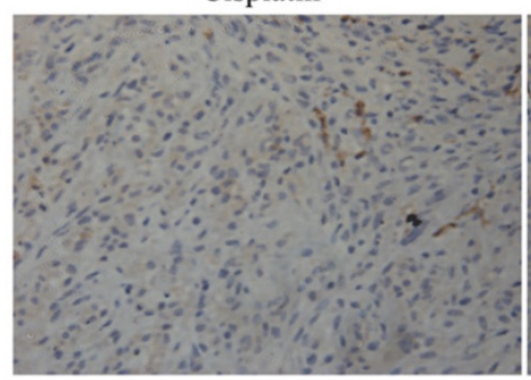

PBS

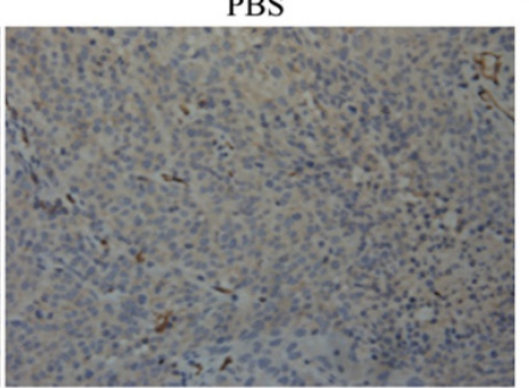

G

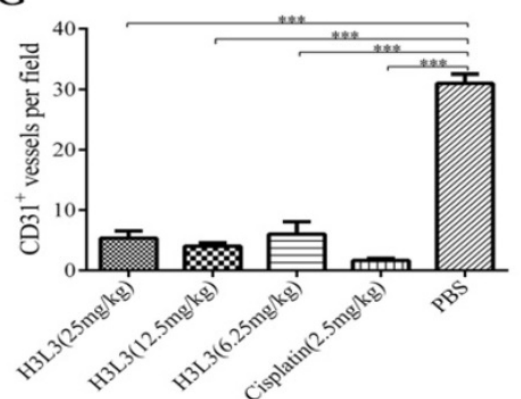

Figure 4. The inhibitory effects of H3L3 on the tumor growth in vivo. (A) Changes in tumor volume during the days of the experiment in different groups. (B) Photographs of xenograft tumors formed from $\mathrm{H} 460$ cells in different experiment groups. (C) Histogram showing the volume of different experiment groups. (D) Histogram revealing the inhibition rate of tumor growth in different experiment groups compared to control (PBS). Cisplatin is the positive group. (E) Weight of BABL/c-nu mice were measured every three days during the experiments in different groups. The data are presented as means \pm SD from five mice. (F)Tumor xenografts established from $\mathrm{H} 460$ cells are immunostained for CD31 and analysed for micro-vessel density, treated with $\mathrm{H} 3 \mathrm{~L} 3(25 \mathrm{mg} / \mathrm{kg}), \mathrm{H} 3 \mathrm{~L} 3(12.5 \mathrm{mg} / \mathrm{kg}), \mathrm{H} 3 \mathrm{~L} 3(6.25 \mathrm{mg} / \mathrm{kg}), \mathrm{Cisp} / \mathrm{atin}(2.50 \mathrm{mg} / \mathrm{kg})$ and $\mathrm{PBS}$, respectively. (G)Quantification of the micro- vessel density. Data are presented as the mean $\pm \mathrm{SD}$ of three independent experiments performed in triplicate. $* * * \mathrm{P}<0.001$. 


\section{Discussion}

bFGF plays an important role in the growth, metastasis and angiogenesis of tumors including lung cancer, it is a valuable target of investigation[24-26]. Previously, we produced the murine anti-bFGF monoclonal antibody (E12), which could inhibit the metastasis of LLCs, but it existed the heterogeneous and would induce an HAMA response if used in humans. These limitations led us to modify the murine antibody, with the goal of humanizing it to prevent an unwanted immune response while maintaining its affinity and specificity for bFGF, and its stability. More importantly, humanization is widely applicable due to its well-developed technology and low cost. It occupies a large part of the monoclonal antibody market and has produced promising clinical candidates [27]. Antibodies can be humanized via resurfacing, framework shuffling, phage display approaches and specificity determining residue grafting[28]. Moreover, analysis of the crystal structures of antigen-antibody complexes shows that less than $33 \%$ of CDR residues are directly involved in antigen-antibody interactions and when CDR residues are changed, it can increase affinity for the antigen[29]. However, traditional CDR grafting by transplanting key antigen- recognizing residues from an exogenous antibody onto a human antibody generally produces a humanized antibody that has low immunogenicity or fails to express[30]. Thus, we have produced three strains of human full-length monoclonal antibodies based on E12 using structure-based computational protein design to simulate the crystal structure, which closely resembles the actual structure. Among them, H3L3 has the highest humanization and affinity, and a humanization percent for the heavy and light chains of $100 \%$ and $98.89 \%$, respectively.

Multiple mechanisms have been described to explain how monoclonal antibodies exert their function on tumors. In general, bFGF and FGFRs dimerize leading to a conformational change and the formation of a tetrameric complex on the cell surface, which will activate the downstream signaling pathways. However, from Immunofluorescence and Western blot assays, we found that H3L3 could reduce the expression of $\mathrm{p}$-AKT and p-MAPK in downstream signaling pathways, but could not completely block the binding of bFGF and FGFR1. The affinity of bFGF to FGFR1 is $1.2 \times 10^{-10}$ [31], but H3L3 with FGFR1 is only $1 \times 10^{-9}$, which may be the main reason for the effect of H3L3. Our next step is to clearly define the CDR boundaries to increase the affinity of H3L3 by altering the residues in or around the CDR based on homology modeling.
Most tumors are sensitive to chemotherapy during the first round of treatment, but recurrent tumors often develop drug resistance, which is a major hurdle to successful therapies. Targeted therapy using humanized antibodies is beneficial for individualized and precise treatment of tumors. Angiogenesis is controlled by multiple signaling pathways, including bFGF and VEGF or PDGF, making treatment with single-target anti-vascular drugs impractical[32-34]. Treatments targeting multiple signaling pathways simultaneously have been and continue to be developed to face this challenge. In addition, by enabling the simultaneous engagement of two distinct targets, bispecific antibodies can broaden the potential utility of antibody-based therapies[35, 36]. Along these lines, application of H3L3 in combination with other drugs could provide personalized treatments. Combination therapy may be a promising and effective strategy to suppresses cancer progression by simultaneously acting on different targets, which could achieve better therapeutic outcomes for patients.

Collectively, our data demonstrate that the human full-length monoclonal antibody H3L3, with humanization of light and heavy chains of $100 \%$ and $98.89 \%$, respectively, could bind to bFGF comparably to the murine monoclonal antibody E12. In addition, H3L3 could effectively suppress tumor progression in vitro and in vivo. H3L3 may be a promising antibody to block the progression of NSCLC.

\section{Supplementary Material}

Supplementary figures and tables.

http://www.jcancer.org/v09p2003s1.pdf

\section{Acknowledgements}

This study was funded by grants from the National Natural Science Foundation of China, No. 81202449; and Guangdong Province Key Scientific Research Grant, No. 2013A022100031.

\section{Ethical approval}

All applicable international, national and or institutional guidelines for the care and used of animals were followed.

\section{Competing Interests}

The authors have declared that no competing interest exists.

\section{References}

1. Cetin K, Ettinger DS, Hei YJ, O'Malley CD. Survival by histologic subtype in stage IV nonsmall cell lung cancer based on data from the Surveillance, Epidemiology and End Results Program. Clinical epidemiology. 2011; 3: 139-48.

2. Lin JM, Zhao JY, Zhuang QC, Hong ZF, Peng J. Xiongshao capsule promotes angiogenesis of HUVEC via enhancing cell proliferation and up-regulating the 
expression of bFGF and VEGF. Chinese journal of integrative medicine. 2011; 17: 840-6.

3. Sukmana I, Vermette P. The effects of co-culture with fibroblasts and angiogenic growth factors on microvascular maturation and multi-cellular lumen formation in HUVEC-oriented polymer fibre constructs. Biomaterials. 2010; 31: 5091-9.

4. Boyd SR, Tan DS, de Souza L, Neale MH, Myatt NE, Alexander RA, et al. Uveal melanomas express vascular endothelial growth factor and basic fibroblast growth factor and support endothelial cell growth. The British journal of ophthalmology. 2002; 86: 440-7.

5. Plotnikov AN, Schlessinger J, Hubbard SR, Mohammadi M. Structural basis for FGF receptor dimerization and activation. Cell. 1999; 98: 641-50.

6. Eswarakumar VP, Lax I, Schlessinger J. Cellular signaling by fibroblast growth factor receptors. Cytokine \& growth factor reviews. 2005; 16: 139-49.

7. Turner N, Grose R. Fibroblast growth factor signalling: from development to cancer. Nature reviews Cancer. 2010; 10: 116-29.

8. Akl MR, Nagpal P, Ayoub NM, Tai B, Prabhu SA, Capac CM, et al. Molecular and clinical significance of fibroblast growth factor 2 (FGF2/bFGF) in malignancies of solid and hematological cancers for personalized therapies. Oncotarget. 2016; 7: 44735-62.

9. Dirix LY, Vermeulen PB, Pawinski A, Prove A, Benoy I, De Pooter C, et al. Elevated levels of the angiogenic cytokines basic fibroblast growth factor and vascular endothelial growth factor in sera of cancer patients. British journal of cancer. 1997; 76: 238-43.

10. Sezer O, Jakob C, Eucker J, Niemoller K, Gatz F, Wernecke K, et al. Serum levels of the angiogenic cytokines basic fibroblast growth factor (bFGF), vascular endothelial growth factor (VEGF) and hepatocyte growth factor (HGF) in multiple myeloma. European journal of haematology. 2001; 66: 83-8.

11. Iwasaki A, Kuwahara M, Yoshinaga Y, Shirakusa T. Basic fibroblast growth factor (bFGF) and vascular endothelial growth factor (VEGF) levels, as prognostic indicators in NSCLC. European journal of cardio-thoracic surgery : official journal of the European Association for Cardio-thoracic Surgery. 2004; 25: $443-8$

12. Bodner-Adler B, Mayerhofer K, Czerwenka K, Kimberger O, Koelbl H, Bodner $\mathrm{K}$. The role of fibroblast growth factor 2 in patients with uterine smooth muscle tumors: an immunohistochemical study. European journal of obstetrics, gynecology, and reproductive biology. 2016; 207: 62-7.

13. Cihoric N, Savic S, Schneider S, Ackermann I, Bichsel-Naef M, Schmid RA, et al. Prognostic role of FGFR1 amplification in early-stage non-small cell lung cancer. British journal of cancer. 2014; 110: 2914-22.

14. Brown WS, Akhand SS, Wendt MK. FGFR signaling maintains a drug persistent cell population following epithelial-mesenchymal transition. Oncotarget. 2016; 7: 83424-36

15. Xiao XY, Lang XP. Correlation Between MMP-7 and bFGF Expressions in Non-small Cell Lung Cancer Tissue and Clinicopathologic Features. Cell biochemistry and biophysics. 2015; 73: 427-32.

16. Bremnes RM, Camps C, Sirera R. Angiogenesis in non-small cell lung cancer: the prognostic impact of neoangiogenesis and the cytokines VEGF and bFGF in tumours and blood. Lung cancer (Amsterdam, Netherlands). 2006; 51: $143-58$.

17. de Aguiar RB, Parise CB, Souza CR, Braggion C, Quintilio W, Moro AM, et al. Blocking FGF2 with a new specific monoclonal antibody impairs angiogenesis and experimental metastatic melanoma, suggesting a potential role in adjuvant settings. Cancer letters. 2016; 371: 151-60.

18. Cai $Y$, Zhang $J$, Lao $X$, Jiang $H, Y u, Y$, Deng $Y$, et al. Construction of a disulfide-stabilized diabody against fibroblast growth factor- 2 and the inhibition activity in targeting breast cancer. Cancer science. 2016; 107: 1141-50

19. Pardo OE, Latigo J, Jeffery RE, Nye E, Poulsom R, Spencer-Dene B, et al. The fibroblast growth factor receptor inhibitor PD173074 blocks small cell lung cancer growth in vitro and in vivo. Cancer research. 2009; 69: 8645-51.

20. Shkoporov AN, Khokhlova EV, Savochkin KA, Kafarskaia LI, Efimov BA. Production of biologically active $\mathrm{scFv}$ and $\mathrm{VHH}$ antibody fragments in Bifidobacterium longum. FEMS microbiology letters. 2015; 362: fnv083.

21. Yang Y, Luo Z, Qin Y, Zhou Y, Gong L, Huang J, et al. Production of bFGF monoclonal antibody and its inhibition of metastasis in Lewis lung carcinoma. Mol Med Rep. 2017; 16: 4015-21.

22. Zhang L, Huo X, Liao Y, Yang F, Gao L, Cao L. Zeylenone, a naturally occurring cyclohexene oxide, inhibits proliferation and induces apoptosis in cervical carcinoma cells via PI3K/AKT/mTOR and MAPK/ERK pathways. Scientific reports. 2017; 7: 1669 .

23. Nakashio A, Fujita N, Tsuruo T. Topotecan inhibits VEGF- and bFGF-induced vascular endothelial cell migration via downregulation of the PI3K-Akt signaling pathway. International journal of cancer. 2002; 98: 36-41.

24. Yu M, Li SY, Yu Z, Qiu XS, Hou P, Wang EH, et al. [Clinical significance of heparanase and basic fibroblast growth factor expression in human non-small cell lung cancer]. Zhonghua bing li xue za zhi $=$ Chinese journal of pathology. 2005; 34: 36-41.

25. Kuhn H, Kopff C, Konrad J, Riedel A, Gessner $\mathrm{C}$, Wirtz H. Influence of basic fibroblast growth factor on the proliferation of non-small cell lung cancer cell lines. Lung cancer (Amsterdam, Netherlands). 2004; 44: 167-74.

26. Formisano L, Jansen VM, Marciano $R$, Bianco R. From biology to therapy: Improvements of therapeutic options in Lung cancer. Anti-cancer agents in medicinal chemistry. 2017
27. Greulich H, Pollock PM. Targeting mutant fibroblast growth factor receptors in cancer. Trends in molecular medicine. 2011; 17: 283-92.

28. Bernett MJ, Karki S, Moore GL, Leung IW, Chen H, Pong E, et al. Engineering fully human monoclonal antibodies from murine variable regions. Journal of molecular biology. 2010; 396: 1474-90.

29. Almagro JC. Identification of differences in the specificity-determining residues of antibodies that recognize antigens of different size: implications for the rational design of antibody repertoires. Journal of molecular recognition : JMR. 2004; 17: 132-43.

30. Zhang T, Wu MR, Sentman CL. An NKp30-based chimeric antigen receptor promotes $\mathrm{T}$ cell effector functions and antitumor efficacy in vivo. Journal of immunology (Baltimore, Md : 1950). 2012; 189: 2290-9.

31. Takayama S, Murakami S, Nozaki T, Ikezawa K, Miki Y, Asano T, et al. Expression of receptors for basic fibroblast growth factor on human periodontal ligament cells. Journal of periodontal research. 1998; 33: 315-22.

32. Hu PH, Pan LH, Wong PT, Chen WH, Yang YQ, Wang H, et al. (125)I-labeled anti-bFGF monoclonal antibody inhibits growth of hepatocellular carcinoma. World journal of gastroenterology. 2016; 22: 5033-41.

33. Ramjiawan RR, Griffioen AW, Duda DG. Anti-angiogenesis for cancer revisited: Is there a role for combinations with immunotherapy? Angiogenesis. 2017; 20: 185-204.

34. Wang Z, Dabrosin C, Yin X, Fuster MM, Arreola A, Rathmell WK, et al. Broad targeting of angiogenesis for cancer prevention and therapy. Semin Cancer Biol. 2015; 35 Suppl: S224-s43.

35. Spiess C, Merchant M, Huang A, Zheng Z, Yang NY, Peng J, et al. Bispecific antibodies with natural architecture produced by co-culture of bacteria expressing two distinct half-antibodies. Nature biotechnology. 2013; 31: 753-8.

36. Yu YJ, Zhang Y, Kenrick M, Hoyte K, Luk W, Lu Y, et al. Boosting brain uptake of a therapeutic antibody by reducing its affinity for a transcytosis target. Science translational medicine. 2011; 3: 84ra44. 